\section{Response to Coceani et al.}

Advance online publication, 14 June 2017; doi:10.1038/pr.2017.125

To the Editor: We appreciate the comments of Drs. Coceani, Scebba, and Angeloni. We agree with their point that alterations in calcium entry and sensitization are significant components of the increase in ductus tension that occurs with advancing gestation. As Drs. Coceani, Scebba, and Angeloni point out, the Rho family of GTPases, which affect calcium sensitization by activating Rho kinase and inhibiting myosin phosphatase (1), has been implicated in ductus arteriosus constriction by a number of investigators (2). Our previous work (3) also showed that there was a significant difference in Rho kinase activity between the immature and mature ductus. However, in contrast with the increase in RhoB gene expression that Dr. Coceani observed with advancing gestation in fetal rats, we have not been able to demonstrate a similar increase in RhoB expression in fetal sheep (neither in our earlier studies (using quantitative PCR) (2) nor in our current study (using oligonucleotide microarray) (4)). Moreover, contrary to Dr. Coceani's comment that we missed the finding because of our approach of paired comparison, that is not the case. We examined significantly altered genes by conducting the comparison of near-term fetus ductus versus newborn ductus and failed to observe a significant change in RhoB mRNA expression (see complete datasets Gene Expression Omnibus Accession No. GSE87840). The most obvious explanation for the different results might be that different species were used for our experimental models. While changes in calcium entry and sensitization appear to account for the developmental increase in ductus tension with advancing gestation, the way this is accomplished seems to vary according to the species that is studied. For example, using quantitative PCR, we previously found that with advancing gestation RhoB expression is significantly increased in human (5) and mouse (unpublished results) ductussimilar to what Dr. Coceani's laboratory observed in fetal rats. However, in sheep $(3,4)$ ) and baboon (unpublished results) ductus there was no increase or decrease in RhoB expression. Although we have not examined the expression of calmodulin by quantitative PCR among the different species, it is quite possible that its expression might also vary depending on the species studied.

\section{Ravi Goyal ${ }^{1}$ and Ronald I. Clyman ${ }^{2}$}

${ }^{1}$ Center for Perinatal Biology, Division of Basic Sciences, Loma Linda University, Loma Linda, California, USA; ${ }^{2}$ Department of Pediatric and Cardiovascular Research Institute, University of California San Francisco, San Francisco, California, USA.

Correspondence: Ravi Goyal (rgoyal@llu.edu)

\section{REFERENCES}

1. Somlyo AP, Somlyo AV. Ca2+ sensitivity of smooth muscle and nonmuscle myosin II: modulated by G proteins, kinases, and myosin phosphatase. Physiol Rev 2003;83:1325-58.

2. Costa M, Barogi S, Socci ND, et al. Gene expression in ductus arteriosus and aorta: comparison of birth and oxygen effects. Physiol Genomics 2006;25:250-62.

3. Clyman RI, Waleh NS, Kajino H, Roman C, Mauray F. Calcium-dependent and calcium-sensitizing pathways in the mature and immature ductus arteriosus. Am J Physiol Regul Integr Comp Physiol 2007;293:R1650-6.

4. Goyal R, Goyal D, Longo LD, Clyman RI. Microarray gene expression analysis in ovine ductus arteriosus during fetal development and birth transition. Pediatr Res 2016;80:610-8.

5. Waleh N, Hodnick R, Jhaveri N, et al. Patterns of gene expression in the ductus arteriosus are related to environmental and genetic risk factors for persistent ductus patency. Pediatr Res 2010;68:292-7. 